\title{
EL LATÍN EN LAS INSCRIPCIONES BAJOMEDIEVALES*
}

\author{
MAURILIo PÉREZ GoNZÁLEZ \\ Universidad de León \\ mperg@unileon.es
}

\section{RESUMEN}

Estudio lingüístico y literario de algunas inscripciones representativas de la Baja Edad Media (1250-1450) en las provincias de Asturias, Zamora, Palencia, Segovia y Ávila. De las cinco provincias se proporcionan previamente unos datos generales sobre sus epígrafes medievales. La conclusión general es que en el s. XIII y siguientes persiste la calidad alcanzada en el s. XII tras la llegada de los monjes cluniacenses. El autor finaliza defendiendo la interdisciplinariedad científica y la necesidad de unos amplios conocimientos filológicos que permitan aplicar adecuadamente la crítica textual epigráfica: sólo así la epigrafía medieval podrá contribuir a descifrar la verdad histórica.

PALABRAS ClAVE: epigrafía, latín medieval, baja Edad Media, crítica textual.

\section{ABSTRACT}

This is a linguistic and literary study of some representative inscriptions from the Late Middle Ages (1250-1450) in the provinces of Asturias, Zamora, Palencia, Segovia and Ávila. Background information about those provinces' medieval epigraphs is previously given. The general conclusion is that in the 13th century and afterwards, the quality reached in the 12 th century stays with the arrival of Cluniac monks. The author

* Este trabajo forma parte de los Proyecto de Investigación HUM2006-01430/FILO (Ministerio de Educación y Ciencia) y LE026A07 (Junta de Castilla y León). 
concludes with the defence of the scientific interdiscipline and the need of deep philological knowledge, which allows to apply textual criticism in epigraphs properly: this is the only way medieval epigraphy will be able to contribute to decipher the historical truth.

Key Words: epigraphy, Medieval Latin, Late Middle Ages, textual criticism.

0. El año 1999 la Universidad de León y la editorial Brepols editaron el volumen I/2 del Corpus Inscriptionum Hispaniae Mediaevalium dirigido por el Prof. Dr. D. Vicente García Lobo, volumen que contiene un estudio epigráfico del Dr. Maximino Gutiérrez Álvarez y otro filológico escrito por mí y que comienza asíl: «Hace ya unos cuantos años, el Dr. D. Vicente García Lobo, catedrático de Paleografía de la Universidad de León, gran defensor de la interdisciplinariedad científica, nos propuso formar parte, desde nuestro campo de estudio, de un grupo de investigación dispuesto a trabajar en torno a las inscripciones medievales castellano-leonesas, con el objeto de salvaguardar para nuestro acervo cultural lo más que pudiésemos de ellas... A pesar de que en aquel momento teníamos pendientes de realización varios proyectos de trabajo, ...aceptamos de buena gana su amable propuesta».

Mucho más recientemente, el año 2004, en las actas del Congreso de las lenguas romances en el reino de León. Siglos IX-XII, decía ${ }^{2}$ : «...la información filológica aportada por un epígrafe medieval de tres o cuatro líneas suele ser muy superior a la de un diploma que ocupe página y media o dos páginas. Sin duda, es urgente y necesario que se publique el corpus epigráfico medieval de nuestro país, tal como se ha hecho en Alemania o se está haciendo en Francia desde 1977. Estoy totalmente convencido de que el día en que contemos con dicho corpus la opinión general sobre la Edad Media de España cambiará en buena parte».

Sigo pensando exactamente igual por una razón extraordinariamente simple: El trasiego humano en la España medieval (sobre todo hasta los primeros años del reinado de Alfonso VII), con ejércitos cristianos invadiendo los territorios musulmanes casi cada primavera o con ejércitos musulmanes invadiendo territorios cristianos, tuvo que suponer una irreparable y constante, casi instantánea, pérdida de escritos en pergamino, pero no de epígrafes. Además, dicha pérdida afectaría sobre todo a los escritos más literarios, menos prosaicos. ¿Qué familia medieval, al tener que huir precipitadamente por la inminente llegada del enemigo, salvaría antes una obra literaria que sus cédulas de propiedad? He aquí una razón que explica en parte la pobreza literaria de la España del s. XII en comparación con la riqueza literaria de la Francia del s. XII, que personalmente considero para la Europa Occidental tan importante o más que la Italia humanística de los siglos XIV y XV.

Lo mismo que cuando por primera vez me comprometí a trabajar en el latín epigráfico medieval, también ahora me encuentro inmerso en proyectos que considero sumamente necesarios, cual es la elaboración y redacción de un diccionario latino-romance del

\footnotetext{
1 PÉrez GonZÁlez, 1999: 155.

2 PÉrez GonZÁlez, 2004: 323.
} 
reino de León (s. VIII-1230), que parcialmente verá la luz el año $2010^{3}$. Pero confieso públicamente que el Prof. García Lobo, hace ahora unos veinte años, logró hacerme ver la necesidad de la interdisciplinariedad científica y la extraordinaria importancia de la epigrafía medieval, a la que siempre vuelvo. Y sigue haciéndolo, como pone de manifiesto el presente trabajo.

1. En la citada publicación de 1999, sólo referida a las inscripciones medievales de la provincia de Zamora, expuse unos presupuestos filológicos en los que observaba la necesidad de tener en cuenta la repartición de epígrafes por siglos, el número de inscripciones en latín y en romance y su distribución temporal, cuántas inscripciones son originales y cuántas son copias cercanas al original o modernas, qué transcripciones son paleográficas o no paleográficas, etc. ${ }^{4}$. Son presupuestos tan imprescindibles de conocer como enojosos de elaborar. En este trabajo tales presupuestos se referirán a las inscripciones ya publicadas de las provincias de Oviedo y Zamora, a las de la provincia de Palencia, que la Dra. Encarnación Martín publicará, a las de la provincia de Segovia, recopiladas por el Dr. Lorenzo Martínez Ángel con ocasión de su memoria de Licenciatura y de su posterior tesis doctoral, y a las de la provincia de Ávila, recopiladas por el Dr. Santiago Domínguez y ya listas para ser publicadas. Doy las gracias aquí a la Dra. Encarnación Martín y al Dr. Santiago Domínguez por las facilidades que ambos me han dado para consultar su corpus de inscripciones palentinas y abulenses.

Pero los citados presupuestos filológicos de las inscripciones medievales de estas cinco provincias, juntos y por separado, no puedo precisarlos en este momento porque en dos casos (Palencia y Ávila) pertenecen a obras todavía no publicadas y que, en consecuencia, podrían incluir adiciones de última hora. Además, el resultado, aunque muy provechoso, sería una exposición sumamente árida. Por ello, de las inscripciones de cada provincia sólo indicaré unos cuantos datos generales, para después dedicarme en cada provincia a observar el tipo de latín de algunas inscripciones bajomedievales, cual reza en el título del trabajo. Llamo así a las inscripciones comprendidas entre los años 1200 y 1450, pues después de esta fecha considero que ya hay que hablar de inscripciones prerrenacentistas.

2. La más importante de las cinco colecciones epigráficas citadas es, sin duda alguna, la colección epigráfica de la provincia de Asturias, que cuenta con unas trescientas inscripciones medievales, incluidas las visigodas. También es la colección más rica de las cuatro, siendo numerosísimos los epígrafes versificados. Las inscripciones bajomedievales son unas setenta, que mayoritariamente están en verso, lo que pone de manifiesto la cultura de la zona. A continuación comentamos literaria y linguiísticamente dos inscripciones bajomedievales del corpus asturiano.

2.1. La primera de ellas tiene el $n^{\circ} 66$ de la colección ${ }^{5}$. Está ubicada en la sala capitular de la catedral de Oviedo. Es un epitafio referido al cantor Pedro Estébanez, fallecido el año 1293. Texto:

${ }^{3}$ Este Proyecto de Investigación está siendo posible gracias a varias y consecutivas ayudas de la Junta de Castilla y León y del Ministerio de Educación y Ciencia (o de Ciencia y Tecnología).

4 Pérez González, 1999: 156-160.

5 Diego Santos, 1984: 97. 
P $\underline{e r}$ Stephani, gratus cantor, iacet hic tumulatus, $/ 2$ diues, magniffic $\underline{u s}$ et amici uerus amicus. $/{ }^{\beta}$ Huius erat cura tenpli deffe $\underline{n d e r e}$ iura, $/{ }^{4}$ et quia tot uoluit p $\underline{\operatorname{rob}}$ bitates semper habere, $/{ }^{5}$ nos merito monuit nimium sua funera flere. $/{ }^{6}$ Filius ergo Dei compaciat $\underline{u r}$ ei. Amen. $/^{7}$ Mille $\mathrm{C}$ ter numera post $\mathrm{X}$ ter et I dabat era.

Traducción: «Aquí yace enterrado Pedro Estébanez, chantre $e^{6}$ afable, rico, espléndido y verdadero amigo del amigo. Su preocupación era defender los derechos del templo, y puesto que quiso tener siempre tantas bondades, merecidamente su muerte nos ha impulsado muchísimo a llorar. Por tanto, que el Hijo de Dios se apiade de él. Amén. Corría la era 1331 (= año 1293)».

El latín de este epitafio se corresponde perfectamente con el de la segunda mitad del s. XIII: formas como Per, Stephani, magnifficus y compaciatur nos dicen, en conjunto, que ya se han sobrepasado los primeros decenios del s. XII. Por lo demás, la originalidad en la expresión de la fecha fue frecuente durante toda la Edad Media (recuérdese la forma de expresar la era en algunas incripciones del s. X: cf. San Miguel de Escalada, San Martín de Castañeda, etc.).

El epitafio consta de siete líneas, de las que las cinco primeras son otros tantos versos leoninos con rima bisilábica. Como fácilmente puede observarse, la rima de cada uno de los tres primeros versos leoninos se produce entre la pentemímeris y el final de verso: átus... -átus; -icus... -icus; y -úra... -úra. En los dos últimos versos riman las pentemímeris entre sí (-ÓLUIT) y los finales de verso entre sí (-ERE). También se observan algunas particularidades prosódicas, como el alargamiento de una sílaba breve ante cesura (magnificūs ante vocal y nom. sing. curā por cură ante vocal). La oración desiderativa de la línea 6 ( $\sin$ amen) parece un pentámentro, parecer al que me empujan tanto la prosodia como la existencia de rima. Por último, la fecha final queda al margen de la versificación, pues está escrita en prosa rimada y rítmica (ter numéra... dabat éra). Reproduzco la inscripción disponiéndola por versos, con sus cesuras y rimas y demás particularidades:

${ }^{1}$ Per Stephani, grÁTUS / cantor, iacet hic tumulÁTUS, //

2 diues, magniffIC $\underline{U S}$ / et amici uerus amICUS. //

${ }^{3}$ Hui us erat cÚRA / tenpli deffendere iÚRA ,//

${ }^{4}$ et quia tot uÓLUIT / p $\underline{r}$ obitates semper h $\underline{a b}$ ÉRE, //

${ }^{5}$ nos merito mÓNUIT / nimiu $\underline{m}$ sua funera flÉRE. //

${ }^{6}$ Filius ergo Dei / compaciatur ei, /// amen.

${ }^{7}$ Mille $\mathrm{C}$ ter numéra post $\mathrm{X}$ ter et I dabat éra.

2.2. La segunda inscripción asturiana que voy a comentar tiene el $\mathrm{n}^{\circ} 115$ de la colección ${ }^{7}$. Está ubicada en el presbiterio de la iglesia de las Pelayas de Oviedo. Es un epitafio referido a la abadesa Sancha Fernández, fallecida el año 1337. Texto:

In fouea mortis gregis custodia fortis $/^{2}$ clauditur, est ideo commemorata Deo. $\beta^{\beta} \mathrm{Hec}$ merito moris gradu $\underline{m}$ quesiuit honoris. $/{ }^{4} \mathrm{Si}$ gen $\underline{u s}$ hanc decorat, satis illam fama decorat. $/{ }^{5}$ Sancia Fernandi nomine dicta fuit. $/^{6} \mathrm{Vt}$ sit luce sita corde precemur ita, $\Gamma^{7}$ que obiit mense Aug $\underline{\underline{u}} \underline{\underline{u}} \mathrm{i}$ era M CCC LXXV.

\footnotetext{
6 PÉrez Rodríguez, 2003: 85-90.

7 Diego Santos, 1984: 128-129.
} 
Traducción: «En el foso de la muerte está encerrada la valiente guardiana de la grey, por lo que es recordada ante Dios. Gracias al mérito de su honradez adquirió el grado del honor. Si su linaje la realza, la fama la honra igualmente. Sancha Fernández fue llamada por nombre. Pidamos de corazón que sea colocada en el reino de la luz. Murió en el mes de agosto en la era 1375 (= año 1337)».

El ordinator debió de encontrar muchas dificultades en su labor creativa, puesto que el resultado ha sido una composición métrica muy extraña. En efecto, las líneas 1 y 2 forman un dístico elegíaco, las líneas 3 y 4 forman sendos hexámetros y las líneas 5 y 6 son pentámetros. Da la impresión de que el autor intentó componer tres dísticos elegíacos, pero que después del primer dístico optó, ante las dificultades, por componer dos hexámetros leoninos seguidos de dos pentámetros. Con esto el autor nos indica claramente su intención, pero también sus limitaciones. Otra limitación más consiste en que todos los versos tienen rima bisilábica consonante, excepto el quinto, que tiene rima monosilábica asonante (-i...-it). Por último, la línea o verso 4 repite la forma verbal dĕ/cŏrat, inadmisible en el último pie del hexámetro, por lo que probablemente dĕ/cŏrat esté en lugar de hŏ/nōrat ${ }^{8}$. Pero este error parece mucho más propio del lapicida que del ordinator. Reproduzco la inscripción disponiéndola por versos, con sus cesuras y rimas y con la citada observación de crítica textual epigráfica:

${ }^{1}$ In fouea mÓRTIS / gregis custodia fÓRTIS //

${ }^{2}$ clauditur, est idEO / commemorata DEO. //

${ }^{3}$ Hec merito mÓRIS / g $\underline{r a}$ du $\underline{m}$ quesiuit honÓRIS. //

${ }^{4} \mathrm{Si}$ gen $\underline{u s}$ hanc decORAT, / satis illa $\underline{\underline{m}}$ fama honÓRAT (memÓRAT?). //

${ }^{5}$ Sancia FernandI / nomine dicta fuIt. //

${ }^{6}$ Ut sit luce sÍTA/corde precemur ÍTA, ///

${ }^{7}$ que obii mense Augusti era M CCC LXXV.

3. Las inscripciones bajomedievales de la provincia de Zamora son unas ochenta, es decir, más del $50 \%$ de todas las inscripciones medievales zamoranas, 151 en total. En la primera mitad del s. XIII las inscripciones siguen siendo sobre todo latinas, no predominando las romances más que a partir de la segunda mitad de dicho siglo. Al fin y al cabo, todo sucede como en la documentación diplomática coetánea. El latín de tales inscripciones es plenamente medieval, es decir, más clásico y normativo que el latín de las inscripciones anteriores al s. XII, pero no tan correcto como el latín de las inscripciones prerrenacentistas o renacentistas.

Como ejemplo de estas inscripciones sólo voy a analizar aquí una, la nº 40 del citado corpus ${ }^{9}$, en el que he estudiado otros muchos epígrafes. Dice así:

P $\underline{e r}$ q $\underline{u} \underline{m}$ fundat $\underline{u s}$ loc $\underline{u s}$ e $\underline{s t}, / 2$ iacet hic tumulat $\underline{u s}$ Pe/3trogoris nat $\underline{u s}$ Aldouin $\underline{u s q u e} /{ }^{4}$ uocat $\underline{u s}$, morib $\underline{u s}$ ornat $\underline{\underline{u}}$, fa/ $/ 5$ ma uitaque probat $\underline{u s}$, qui obiit $/{ }^{6}$ ultima die iunii $\underline{\mathrm{e}} \underline{\underline{a}} \mathrm{M}^{\mathrm{a}} \mathrm{CC}^{\mathrm{a}} / 7 \mathrm{~L}^{\mathrm{a}}$ III ${ }^{\mathrm{a}}$.

${ }^{8}$ Hŏ/nōrat o (incluso mejor) mĕ/mōrat, que en las inscripciones cristianas de Diehl se registra con -⿳亠丷--, según el ThLL, s.v. memoro,-are.

9 Gutiérrez Álvarez, 1997: 38-39; Pérez GonZÁlez, 1999: 186. 
Traducción «Aquí yace enterrado quien fundó este lugar, nacido en el Perigod y llamado Aldovino, alabado por sus cualidades, apreciado por su buena fama y por su vida, que murió el último día de junio del año 1215».

Esta inscripción está en verso, constando de tres hexámetros leoninos más la fecha, que, como casi siempre, es amétrica. Los hexámetros leoninos tienen rima bisilábica (-átus), pero de mal gusto por machacona. De todas formas, los hexámetros son cuantitativamente perfectos, si se tiene en cuenta que la sílaba -tus de natus, en la pentemímeris del segundo verso, se encuentra alargada ante la cesura, fenómeno ya frecuente en algunos metros del lat. clásico, el hexámetro entre ellos. Reproduzco la inscripción disponiéndola por versos, con sus cesuras y rimas:

\footnotetext{
${ }^{1}$ Per quem fundÁTUS / locus est, iacet hic tumulÁTUS //

${ }^{2}$ Petrogoris nÁTUS /Aldouinusque vocÁTUS, //

${ }^{3}$ Moribus ornÁTUS, / fama uitaque probÁTUS, //

${ }^{4}$ qui obiit ultima die iunii era $\mathrm{M}^{\mathrm{a}} \mathrm{CC}^{\mathrm{a}} \mathrm{L}^{\mathrm{a}} \mathrm{III}{ }^{\mathrm{a}}$. ///
}

Según Gómez Moreno, probablemente el lapicida cambiase en la primera línea el orden de palabras ideado por el ordinator. Gómez Moreno añade que el orden debería ser per quem locus est fundatus, que, según él, se adapta mejor a la rima ${ }^{10}$. Pero sucede justamente lo contrario: la rima desaparecería en el primer verso sin el orden de palabras per quem fundatus locus est. Dicho en otros términos: Gómez Moreno no se dio cuenta de que este epígrafe fue escrito en hexámetros leoninos.

Es evidente a todas luces que este epitafio se aparta de la redacción normal de los epitafios precisamente en aras de la rima característica del hexámetro leonino. Pero no sólo resulta forzado el orden de palabras, sino que la sintaxis tampoco es plenamente clásica. Por ejemplo, en el latín más clásico se hubiera escrito a quo (c. agente) en vez de per quem, variante que el ordinator ha preferido a pesar de que a quo métricamente consta de dos sílabas largas igual que per quem. Pero esta inscripción no es de la época clásica ni de la humanística, sino de la primera mitad del s. XIII, en el que las lenguas romances emergieron de forma definitiva.

Una última observación respecto a esta inscripción: El enterrado es de origen francés, probablemente un cluniacense de los muchos que pulularon por España a partir de los años finales del s. XI. No voy aquí a insistir en la deuda cultural de Castilla y León con respecto a los cluniacenses, sobre todo los de origen francés.

4. Las inscripciones medievales de la provincia de Palencia recopiladas por la Dra. Encarnación Martín son algunas más de 230. Aunque son bastantes, en términos generales los epígrafes extensos son pocos, así como los lingüística y literariamente llamativos. Además, el uso del latín en la época bajomedieval es escaso. No obstante, voy a comentar dos inscripciones, una en verso y otra en prosa, que ponen de manifiesto la absoluta necesidad de la interdisciplinariedad científica.

4.1. Comento en primer lugar el epitafio sepulcral de doña Inés Rodríguez de Villalobos, esposa de don Pedro Díaz de Castañeda, fallecida el año 1301. Adelanto que el

10 Gómez Moreno, 1980: 172. 
texto plantea bastantes problemas. Encarnación Martín, a la espera de recibir del Museo Arqueológico Nacional una buena fotografía de esta inscripción, provisionalmente debió de tomar el texto de una de las diez o más ediciones anteriores, así como probablemente la traducción. En efecto, da la impresión de que su texto provisional es una refección (con mejoras) de la transcripción de $\mathrm{M}^{\mathrm{a}}$ Ángela Franco Mata, pues apenas divergen. Transcripción de $\mathrm{M}^{\mathrm{a}}$ Ángela Franco Mata ${ }^{11}$ :

Nata de claro: sanguine $/^{2}$ uita sublata : jace hic Angnes tumulata, ${ }^{\beta}$ a $:$ donis fecu(n)da, pia, mitis, crimine munda, $/{ }^{4}$ prudens, facu(n)da, procul est morte secunda. $/{ }^{5}$ Era $\mathrm{M}^{\mathrm{a}} \ldots \mathrm{L}: \mathrm{CC}^{\mathrm{a}}$ $\mathrm{XX}^{\mathrm{a}} \ldots \mathrm{X}$ : IX.

Traducción provisional de Encarnación Martín: «Yace enterrada aquí debajo Inés, nacida de sangre ilustre, cual Adonis fecunda, piadosa, dulce, libre de pecado, prudente, elocuente, está lejos de una segunda muerte. Año 1309».

Es evidente que el texto provisional de Encarnación Martín mejora la transcripción de $\mathrm{M}^{\mathrm{a}}$ Ángela Franco Mata. Pero ambas hacen caso omiso de la más antigua edición, la de Quadrado ${ }^{12}$, que dice así:

.....rata de claro sanguine nata, $/ 2$... sublata iacet hic Angnet tumulata, $\mathcal{\beta}^{\beta}$ donis fecunda, pia, mitis, crimine munda, $/ 4$ prudens, facunda, procul est a morte facunda. $/ 5$ Era MCCCXXXIX.

Es cierto que Quadrado yerra al escribir rata en vez de nata, Angnet por Angnes o tumulata/ por tumula/ta. Pero inicia la transcripción con puntos suspensivos, lo que es un claro indicio de que en el s. XIX ya no era posible leer el deteriorado comienzo de este epitafio, al menos según la diminuta fotografía aportada por $\mathbf{M}^{\mathrm{a}}$ Angela Franco Mata ${ }^{13}$. Otro hecho que llama la atención es que Quadrado lee nata al final de la lín. 1.

A la luz de todas las ediciones de este epitafio, es evidente que la lín. 4 (la que precede a la data) es un verso leonino con rima bisilábica -únda. Y lo mismo la lín. 3, que incluso tiene la misma rima, pero que inicialmente me planteó un gravísimo problema, en el supuesto de la lectura $a$ donis = Adonis de algunas ediciones: métricamente Adonis (lectura que se deduce de la traducción) no cabe en el verso, pues la $a$ - es breve. Además, ¿cómo se explica que doña Inés fuera «cual Adonis fecunda»? Tampoco la traducción «fecunda de Adonis» tendría sentido, pues doña Inés, que es dulce, libre de pecado, prudente, etc., no sería promiscua al mismo tiempo. Inmediatamente pensé que el lapicida se habría equivocado como en tantas ocasiones; es decir, mediante el ejercicio de la crítica textual epigráfica concluí que esta tercera línea de la inscripción debía decir donis fecunda «rica en dones», tal como ya leyó Quadrado. Además, de la fotografía incluida por $\mathrm{M}^{\mathrm{a}}$ Ángela Franco Mata en su ya citada obra se puede concluir, aunque a duras penas, que la inscripción dice ...Angnes tumula/ta donis fecunda, a pesar de que ella transcribe ...Angnes tumulata / a donis fecunda.

11 Franco MATA, 1993²: 103. La transcripción de Encarnación Martin cambia acertadamente iace por iacet, fecu(n)da por fecunda (es decir, sin abreviación de la nasal) y mejora la fecha; y, en una segunda versión, a propuesta mía transcribe tumulaß ${ }^{\beta}$, donis en vez de tumulataß ${ }^{\beta}$ donis.

12 QuAdRAdO-PARCERISA, 1989: 162, nota 3.

13 Franco Mata, 19932: 163 (fot. 77B). 
Inicialmente la lín. 1 supuso un enigma para mí. Pero la transcripción de Quadrado, quien lee nata al final de dicha línea, me empujó a deducir e incluso asegurar dos cosas: A) La lín. 1, actualmente rota en su parte final, en 1861 estaría completa, pues de lo contrario Quadrado hubiese puesto puntos suspensivos, lo mismo que en el comienzo de la línea. B) La lín. 1 ha de ser un verso leonino con rima bisilábica -áta, puesto que la lín. 2 es otro verso leonino con rima bisilábica -áta y en el que uita sublata es una expresión participial en ablativo.

Resuelto el final de la lín. 1, la única cuestión pendiente es saber cuáles serían las letras de su inicio, donde faltan entre diez y doce letras, es decir, dos palabras. Y no creo que solucione nada una visita al Museo Arqueológico Nacional para comprobar de nuevo el texto de esta inscripción a la luz de su estudio métrico, pues la fotografía anteriormente citada permite pensar que esas letras iniciales están desgastadas, borradas para siempre, pues ya Quadrado no fue capaz de leerlas.

Sin embargo, gracias a los actuales medios técnicos es posible saber con bastante verosimilitud cuáles serían las aproximadamente diez letras anteriores a -nata, con las que formar las dos palabras iniciales de esta inscripción. Según creo, el epitafio empezaría con la expresión moribus ornata, que extrañamente no se registra en los poetas elegíacos del lat. clásico, tal como se me ha sugerido con cierto fundamento. Pero sí la he encontrado en un epitafio romano del año 528, que dice así ${ }^{14}$ :

Hic requiescit in pace Turtura, C. F., dulcis Petroni coniux, $\rho^{2}$ Deo seruiens unice fidei, amica pacis, castis moribus ormata, $\beta$ communis fidelibus amicis, familiae grata, nutrix natorum $/ 4$ et nunquam amara marito. Quae uixit...

También se registra omnibus ornata en la Palladii historiae monachorum Lauso dedicatae uersio (ca. s. V-VI) ${ }^{15}$ : ita moribus... ornata, ut in semetipsa haberet inaestimabilem quendam custodem propriae castitatis.

En consecuencia, la expresión moribus nata no es desconocida de la latinidad tardía ni de las inscripciones cristianas en los que se ensalzan las virtudes de las difuntas. Tal debe de ser también el caso del epitafio sepulcral de doña Inés Rodríguez de Villalobos, que en consecuencia debe transcribirse así ${ }^{16}$ :

$<$ Moribus or $>$ nata de claro sanguine $<$ nata $>, /^{2}$ ¿uita? sublata, iacet hic Angnes tumulat $/ 3$ ta, donis fecunda, pia, mitis, crimine munda, $/ 4$ prudens, facunda, procul est a morte facunda. $/^{5}$ Era M CCC XXX IX..

De acuerdo con todo lo anteriormente expuesto, el citado epitafio constaba de cuatro versos leoninos con rima bisilábica: -áta en los dos primeros y -únda en el tercero y cuarto, siendo el estudio filológico antes que el epigráfico el que ha contribuido a fijar el texto, que, de acuerdo con el estado actual de la inscripción (no el de la época de Quadrado), debe editarse así desde el punto de vista métrico:

${ }^{14}$ CORP. VI 32049 (ingens tabula marmorea in uilla Borghesia). El epitafio de Turtura va seguido del de su esposo Petronio.

15 Pallad. hist. mon. 1.48 .

16 Obsérvese que todavía muestro entre interrogaciones una duda, al igual que Quadrado, por lo que probablemente no se elimine leyendo directamente la inscripción en el Museo Arqueológico Nacional. 
${ }^{1}<$ Moribus or $>$ nÁTA, / de claro sanguine $<$ nÄTA $>$,/

${ }^{2}$ ¿uita? sublÁTA, / iacet hic Angnes tumulÁTA. //

${ }^{3}$ Donis fecÚNDA, / pia, mitis, criminis mÚNDA, //

${ }^{4}$ prudens, facÚ $\underline{N D A}, /$ procul est a morte secÚNDA. //

${ }^{5}$ Era M CCC XXX IX. ///

Traducción: «Adornada con buenas costumbres, nacida de ilustre linaje, de vida elevada (?), aquí yace enterrada Inés. Fecunda por sus virtudes, piadosa, dulce, libre de pecado, prudente, elocuente, está lejos de la segunda muerte. Año 1309».

4.2. Paso a comentar el epitafio en prosa de Juan de Castromocho, obispo de Palencia, quien murió el año 1397. Esta inscripción está escrita en letra humanística de pleno s. XVI. La pregunta que el epigrafista puede hacerle al filólogo es la siguiente: ¿Este epitafio fue escrito por primera vez en el s. XVI o es copia más o menos fiel de una inscripción coetánea o cercana a la muerte de Juan de Castromocho? Pero veamos el texto antes de contestar:

Ioannes de Castromocho, episcopus $/ 2$ Palentin $\underline{u s}$, qui clerum Castellæ $\beta$ liberum fecit a solutione tri $/{ }^{4}$ buti monetarum tempore Hen $/{ }^{5}$ rici tertii regis, pro quibus me $/{ }^{6}$ moria anniuersaria fit infra $/ 7$ octauas Pentecostes in capite $/{ }^{8}$ cuiuslibet archipresbitera $/{ }^{9}$ tus huius diocesis, obiit mense $/{ }^{10}$ martio, anno Domini M CCC XC VII.

Traducción: «Juan de Castromocho, obispo de Palencia, que liberó al clero de Castilla del pago del tributó monetario en tiempos del rey Enrique III, por cuya memoria se hacen misas de aniversario en las octavas de Pentecostés en la capital de cualquier presbiteriado de esta diócesis, murió en el mes de marzo del año 1397 del Señor».

El latín de este epitafio es lo suficientemente correcto como para poder considerarse del s. XVI. Sin embargo, hay dos detalles, al menos, que nos permiten pensar que está redactado sobre un texto claramente medieval: 1) La preposición infra con el valor de «dentro de» es típicamente medieval. 2) La forma quibus en pro quibus memoria parece un error característico de alguien que lee mal el texto que tiene delante, pues la expresión más apropiada es pro cuius memoria.

5. Las inscripciones medievales de la provincia de Segovia recopiladas por el Dr. Lorenzo Martínez Ángel son 218. En su mayor parte son bajomedievales (unas 65) y prerrenacentistas (unas 125), circunstancia que se explica por dos motivos fundamentales: 1) por la tardía fecha de la repoblación medieval en la provincia de Segovia, que paradójicamente cuenta con suficientes inscripciones islámicas; y 2) por la ausencia de catedral medieval, destruida en el s. XVI. Esta provincia, como las de Zamora y Palencia, tampoco ofrece muchos epígrafes lingüística y literariamente llamativos. No obstante, voy a comentar brevemente tres inscripciones, dos en verso y una en prosa.

5.1. La primera tiene el $n^{\circ} 42$ en la colección diplomática arriba citada. Es un epitafio a la abadesa María González, fallecida el año 1281. Texto ${ }^{17}$ :

${ }_{17}$ Martínez Ángel, 1999: 68-69. 
Sobria, iusta, pia, $/ 2$ Gonsalui dicta Maria $/ 3$ hic tumulata iacet, $/ 4$ uirgo Deoque placet. $/^{5}$ Exenplar morum $/ 6$ fuit abbatissa soror $\underline{\underline{u}} / /^{7}$ quinta manetque $\underline{\text { Deo }}, /{ }^{8}$ nam moritur sub eo. $/^{9}$ Obiit kalendas octobris $/{ }^{10}$ anno Domini millessimo $\mathrm{CC}^{\circ} /{ }^{11} \mathrm{LXXX}^{\circ} \mathrm{p} \underline{\text { rimo. }}$.

Traducción: «Aquí yace enterrada la llamada María González, sobria, justa, piadosa, virgen y agradable a Dios. Modelo de costumbres fue la quinta abadesa de las hermanas, que descansa en Dios, pues está muerta en su regazo. Falleció el primero de octubre del año 1281 del Señor».

Se observa bien que el texto anterior a la data resulta bastante forzado en más de una ocasión (uirgo Deoque placet, quinta manetque Deo, moritur sub eo) y repetitivo (tres referencias a Dios). Esto se debe a que el autor del epitafio lo supeditó todo a la métrica, incluso las líneas del epitafio, que son tantas cuantas pausas hay; es decir, ocho líneas y otras tres más para la data. En este caso nos hallamos ante dos dísticos elegíacos, en los que tanto los dos hexámetros como los dos pentámetros tienen, de forma independiente, rima consonántica bisilábica entre la pausa y el final de cada verso. El primer dístico llega hasta ...placet (lín. 4) y el segundo hasta ...eo (lín. 8). En ambos el pentámetro es técnicamente perfecto. Sabido es que los dísticos suelen tener sentido completo, que es lo que justifica que haya puesto un punto después de ...placet. Reproduzco la inscripción disponiéndola por versos, con sus cesuras y rimas:

${ }^{1}$ Sobria, iusta, pÍA, / Gonsalui dicta MarÍA //

${ }^{2}$ hic tumulata iÁCET, / uirgo Deoque plÁCET. //

${ }^{3}$ Exenplar mÓRUM / fuit abbatissa sorÓR $\underline{U M} / /$

${ }^{4}$ quinta manetque $\mathrm{D} \underline{E} \mathrm{O}$, nam moritur sub ÉO. ///

${ }^{5}$ Obiit kalendas octobris anno Domini millessimo $\mathrm{CC}^{\circ} / \mathrm{LXXX}^{\circ}$ primo.

5.2. La segunda inscripción segoviana que aquí voy a estudiar tiene el $n^{\circ} 50$ en la citada colección diplomática. Es un epitafio de mediados del s. XIII dedicado a Pedro Caro y su familia. Como inmediatamente se verá, plantea bastantes problemas de crítica textual epigráfica. Texto $^{18}$ :

Ossa Petri Cari lector sciat hic tumolari, $/ 2$ coniux et nati sunt ei $\underline{u s}$ ubique locati. ${ }^{3}$ Est Urraca parens, proles D. Car $\underline{u s}$ eorum, $/ 4$ alter natorum Laurenti $\underline{u s}$ estque suorum $/{ }^{5}$ ac Aparicius est nati nomen ali $\underline{u s} . /^{6} \mathrm{Tu}$ defunctor $\underline{u m}$ sis, Christe, misert $\underline{\underline{u s}}$ eor $\underline{u m}$.

En este caso todavía no ofrezco la traducción porque, dadas las dificultades de interpretación, no quiero condicionar a los lectores. Desde luego, este epitafio está en verso. Las lín. 1 y 2 son dos hexámetros leoninos con rima bisilábica entre la pentemímeris y el final de cada verso (-ári... -ári y -áti... -áti). Las lín. 4, 5 y 6 también son hexámetros leoninos con rima bisilábica entre la pentemímeris y el final de cada verso (-órum... órum, -ius... -ius y -órum... -órum). Estas tres últimas líneas no presentan ni una sola particularidad métrica, pues la sílaba -li- de alius puede medirse como larga por tratarse de un gen. sing.

\footnotetext{
18 MARTíNEZ ÁNGEL, 1999: 78-80.
} 
Pero la lín. 3 plantea problemas, pues contiene una D que Quadrado desarrolló por $\mathrm{Di}$ dacus $^{19}$, mientras que el marqués de Lozoya creyó que podía ser Dominicus ${ }^{20}$. En 1995 conjeturé $^{21}$ que D era la abreviatura de Dei, pues, midiendo Dei como una sola sílaba larga, esta línea puede considerarse un hexámetro, aunque carente de rima y, en consecuencia, no es un hexámetro leonino. Pero ahora entiendo que D esconde un nombre propio de dos sílabas, con lo que la lín. 3 tiene un sentido bastante claro: «Urraca es la madre, hijo de ellos es D. Caro». Desde luego, D no se puede desarrollar por Dominicus, donde sobran dos sílabas; y tampoco por Dei, pues en este caso no hay forma de comprender el contenido de la lín. 3. Y aunque en sentido estricto tampoco puede admitirse la opinión de Quadrado, para quien D = Didacus, sin embargo en sentido amplio existe la posibilidad de que D equivalga a la forma romance de lat. Didacus, es decir, a Diaco o Diago, puesto que la oclusiva sonora - $d$ - fricatizó y posteriormente desapareció, resultando una forma romance de dos sílabas, que son las que precisa este verso para ser un hexámetro.

De todos modos, da la impresión de que el ordinator tuvo serias dificultades para elaborar la lín. 3, pues no logró hacer un hexámetro leonino, sino sólo un hexámetro sin rima. Es posible que el ordinator, al tener problemas en la elaboración del hexámetro leonino, dejase la lín. 3 mal elaborada con la esperanza de arreglarla más tarde, pero, por lo que fuese, no la reelaboró. En conclusión, pienso que la lín. 3 debe considerarse un locus mendosus y, en consecuencia, no debe colocarse entre cruces.

Reproduzco la inscripción disponiéndola por versos, con sus cesuras y rimas, pero a la luz del razonamiento precedente:

Ossa Petri CÁRI / lector sciat hic tumolÁRI, /

coniux et nÁTI / sunt eius ubique locÁTI. /

Est Urraca parens / proles D<iago > Carus eorum, /

Alter natÓRUM / Laurentius estque suÓRUM, /

ac AparicIUS / est nati nomen alIUS. /

Tu defunctÓRUM / sis, Christe, misertus eÓRUM.

Traducción: «Sepa el lector que los huesos de Pedro Caro están enterrados aquí, la esposa y sus hijos están depositados en el (mismo) lugar. Urraca es la madre, hijo de ellos es Diego Caro, otro de sus hijos es Lorenzo, y Aparicio es el nombre de otro hijo. Cristo, compadécete de estos difuntos».

5.3. La tercera inscripción segoviana que voy a estudiar aquí tiene el $n^{\circ} 67$ en la citada colección diplomática ${ }^{22}$. Es un epitafio en prosa a Domingo Aymar y su esposa Sancha. Texto:

[Era M CCC XXXXII]. $/^{2}$ (Christus) Hic iacet Dominicus Ay ${ }^{3}$ mar et uxor eius Sanci ${ }^{4} a$. Obiit et debet uenire $/ 5$ sesmus cum candelis. Quicumque $/{ }^{6}$ hoc sep $\underline{u}$ lcrum uenderit $\underline{u e l}$ emerit $\underline{u e l}$ / aperierit, sit excomunicatus.

19 QuAdrado-PARCERISA, 1993: 48, nota 1.

20 LOZOYA, 1931: 253.

${ }^{21}$ En el acto académico en el que defendió su Memoria de Licenciatura D. Lorenzo Martínez Ángel, «Aproximación a la epigrafía medieval de Segovia. Bibliografía y corpus», León, 1995, 115 páginas.

22 Martínez Ángel, 1999: 99-101. 
Traducción: «Era 1342 (= año 1304). (Christus) Aquí yace Domingo Aymar y su esposa Sancha. Murió y el sexmo ${ }^{23}$ debe venir con velas. Quienquiera que vendiere, comprare o abriere este sepulcro, sea excomulgado».

Por medio de este epitafio sólo quiero subrayar que, como es bien sabido, frecuentemente las inscripciones se relacionan con la documentación diplomática. Buen ejemplo de ello es el párrafo Quicumque... sit excomunicatus de este epitafio, que recuerda fácilmente el comienzo de la fórmula conminatoria en multitud de diplomas medievales.

6. Las inscripciones medievales de la provincia de Ávila recopiladas por el Dr. Santiago Domínguez Sánchez son 143, es decir, menos que las zamoranas y, por supuesto, que las de Palencia y Segovia. Sólo trece son anteriores al s. XIII. Las bajomedievales (1201-1450) son cincuenta; y el resto, ochenta, son prerrenacentistas. Además, de las 50 inscripciones bajomedievales únicamente están en latín cuatro (tres en prosa y una en verso). Pobre balance, pues, el de las inscripciones medievales abulenses.

6.1. No obstante, aquí vamos a comentar el muy extenso epitafio en verso de don Blasco Blázquez, deán de la catedral de Ávila, muerto el 8-VIII-1307. Este epitafio, que ocupa el no 41 en la obra de Santiago Domínguez ${ }^{24}$, lo edito sólo desde el punto de vista métrico, dada su longitud. Texto ${ }^{25}$ :

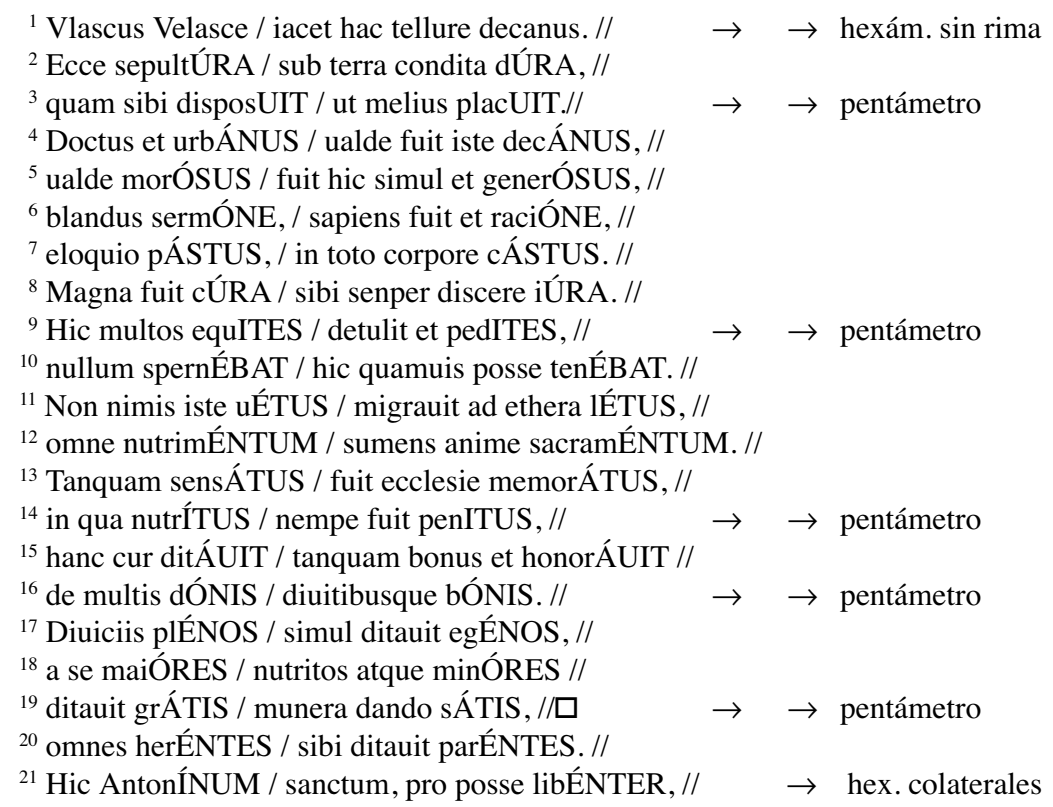

${ }^{23}$ El sexmo es la división territorial que comprendía cierto número de pueblos asociados para la administración de bienes comunes.

${ }^{24}$ Domínguez SÁNCHEZ, pp. 27-30 del texto mecanografiado (supuestamente definitivo).

${ }^{25}$ Santiago Domónguez Sánchez incluye en su obra una transcripción epigráfica y otra paleográfica de este mismo diploma, por lo que me limito a reproducir disponiéndola por versos, con sus cesuras y rimas. 


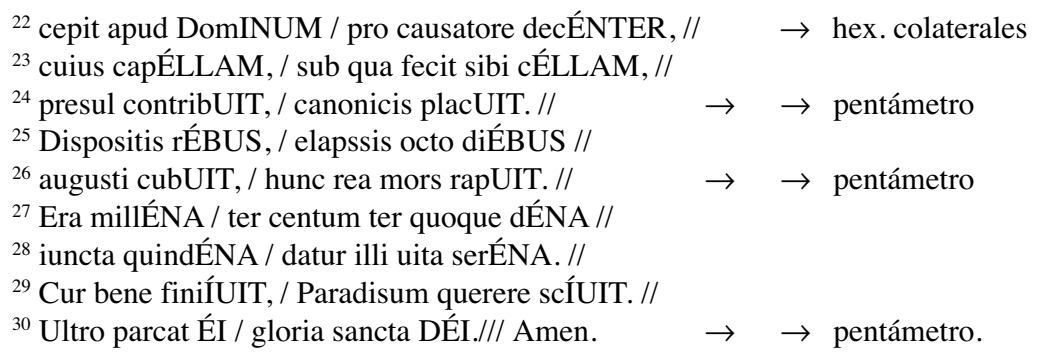

Traducción: «El deán Blasco Blázquez yace en este suelo. He aquí su sepultura construida bajo la firme tierra, que para sí dispuso como mejor le plugo. / [4] Este deán fue en extremo docto y educado, muy exigente a la vez que generoso, persuasivo en la conversación y sabio en el razonamiento, ahíto de elocuencia, casto en todo su cuerpo. / [8] Grande fue siempre su preocupación por conocer las leyes. Lideró a muchos caballeros e infantes, a ninguno desdeñaba a pesar de que tenía el poder de hacerlo. / [11] No demasiado anciano se fue contento al cielo, tomando la Comunión como alimento para el alma. / [13] De modo juicioso se acordó de la Iglesia, en la que sin duda se crió enteramente, por lo que de modo bondadoso la enriqueció y la honró con muchos regalos y grandes riquezas. / [17] Enriqueció con bienes de fortuna a los opulentos y a la vez a los necesitados, de su peculio enriqueció a mayores y a jóvenes dándoles desinteresadamente muchos regalos, enriqueció a sus próximos ${ }^{26}$ y parientes. / [21 Éste, por libre decisión, ante Dios tomó convenientemente a san Antonio como santo patrono, cuya capilla, bajo la que se hizo una celda, la aportó este prelado, lo que agradó a los canónigos. / [25] Dispuesto todo, pasados ocho días de agosto cayó enfermo y la inexorable muerte se lo llevó. En el año 1307 (era mil quinientos treinta más quince) se le concede la vida eterna. / [29] Puesto que acabó bien, supo alcanzar el Paraíso. Que la santa gloria de Dios le preserve en el más allá. Amén».

El latín del presente epitafio muestra las peculiaridades gráfico-fonéticas que son características de los ss. XIII y XIV. Así, el antiguo diptongo ae se registra siempre bajo la forma $e$, no como e caudata (v. 11 ethera y letus, v. 12 anime, v. 20 herentes, etc.). No se observan contracciones ni otros fenómenos vocálicos, excepto la fluctuación en la ausencia / presencia de vocal protónica en Vlascus / Velascus. Ya en el consonantismo, también se observa fluctuación entre $m$ y $n$ ante labial (v. 8 senper / v. 14 nempe), mientras que ante consonante velar sólo hay $n$ (v. 13 y v. 15 tanquam). Persisten las oclusivas aspiradas griegas (v. 11 ethera), la palatalización de -ti- (v. 6 racione, v. 17 diuiciis) y la tendencia a las geminaciones (v. 26 elapssus). También hay que tener en cuenta que la regularidad ortográfica ya es notable, como corresponde a una época en la que, después del renacimiento del s. XII, el uso del latín se ha aposentado como lengua de cultura frente a las lenguas romances.

6. Llegamos ya al momento de las conclusiones, que deben considerarse con precaución desde el punto de vista lingüístico y literario, puesto que aquí sólo se ha estudiado un número muy reducido de inscripciones. Éstas ponen de manifiesto que en el

${ }^{26}$ Posiblemente se pueda traducir «herederos» mejor que «próximos». 
s. XIII y siguientes persiste la calidad lingüística alcanzada en el s. XII a partir de la llegada de los cluniacenses a Castilla y León. Su impronta se observa en la inscripción zamorana de Aldovino de Perigod o en algo tan concreto como la grafía Angnes de la primera inscripción palentina aquí estudiada. Son probablemente los epígrafes palentinos los que mejor muestran el influjo cluniacense.

Pero son otras conclusiones, más generales y de mayor alcance, las que merece la pena subrayar aquí. De todas las posibles voy a ceñirme exclusivamente a tres:

1) La necesidad de la interdisciplinariedad está fuera de discusión en estos momentos: el historiador necesita del paleógrafo o epigrafista, éste del filólogo latinista o hispanista, quien a su vez no debe trabajar al margen de los anteriores. Por ello, los especialistas deben estar totalmente abiertos a las diversas sugerencias de colaboración científica, siempre y cuando reciban tanto cuanto dan. Desde este punto de vista, la generosidad es tan básica como necesaria.

2) Los estudios filológicos constan de tres aspectos igualmente importantes: el lingüístico, el literario y el de la crítica textual, que permite depurar los textos con el fin de entender los hechos en toda su plenitud. Detrás de cada epígrafe o de cada diploma había diversos intervinientes con sus virtudes y defectos, a cuya alma el epigrafista y el diplomatista deben intentar llegar con todos los medios posibles, para de este modo fijar correctamente el texto epigráfico o diplomático, pues si el texto no es correcto, el epigrafista o el diplomatista fallan estrepitosamente. Tal finalidad se malogrará sin conocimientos filológicos, sin hacer crítica textual epigráfica en nuestro caso. La crítica textual epigráfica permite observar todas las particularidades del texto, todas las dificultades, decidir lo que debió ser y no fue. Como ya he dejado entrever, se trata de urgar en el alma del ordinator y demás intervinientes en un epígrafe.

3) El objetivo último de cualesquiera estudios es contribuir en la medida de lo posible a la verdad histórica, a desterrar la falsedad, sea ésta consciente o inconsciente. Según esto, salta a la vista la importancia del estudio de la epigrafía medieval, al menos en Castilla y León, donde sus testimonios presentan una calidad literaria muy superior a la de los diplomas coetáneos. En efecto, los diplomas leoneses y castellanos están plagados de fórmulas que los amanuenses medievales no entendían ni analizaban, por lo que las copiaban con errores flagrantes. Tal es el caso de la fórmula nullius cogentis imperio neque suadentis imperio, que es prácticamente imposible encontrar escrita de forma correcta; o el de la fórmula neque per uim neque per metum, que presenta variantes tan absurdas como non per metu neque per ebrietate, o nec per metum nec per uino nec per nullam ebrietate, etc. Quienes están acostumbrados a leer cotidianamente textos tan disparatados se sentirán aliviados ante la lectura de inscripciones como las aquí estudiadas. Y sin duda pasarán a pensar que nuestra Edad Media no es tan inculta como la mayoría de los diplomas permiten deducir. Por tanto, urge la publicación metódica de las inscripciones medievales hispánicas, actividad que sin duda redundará en beneficio de una mejor opinión sobre el nivel cultural de nuestra Edad Media. 


\section{REFERENCIAS BIBLIOGRÁFICAS}

Diego SAntos, Francisco (1984), Inscripciones medievales de Asturias, Asturias, Principado de Asturias, 293 páginas.

DomíngUEZ SÁNCHEZ, Santiago, «Ávila: Colección epigráfica», Monumenta Palaeographica Medii Aevi, Series Hispanica. Corpus Inscriptionum Mediaevalium, León, Brepols-Univ. León (en prensa).

Franco Mata, Ma Ángela (1993²), Catálogo de la escultura gótica, Madrid, Ministerio de Cultura (Dirección General de Bellas Artes y Archivos), 286 páginas.

Gómez Moreno, Manuel (1980), Catálogo monumental de España. Provincia de Zamora (19031905), León, reedición.

Gutiérrez Álvarez, Maximino (1997), «Zamora: Colección epigráfica», Monumenta Palaeographica Medii Aevi, Series Hispanica. Corpus Inscriptionum Mediaevalium, León, BrepolsUniv. León, 1997, vol. I/1, 205 páginas.

Lozoya, Marqués de (Juan de Contreras y López de Ayala) (1931), «La epigrafía de las iglesias románicas de Segovia», Boletín de la Sociedad Española de Excursiones, 3, pp. 242-258.

Martínez Ángel, Lorenzo (1999), Las inscripciones medievales de la provincia de Segovia, León, Univ. León, dos volúmenes (tesis doctoral en microficha).

PÉrez GonZÁleZ, Maurilio (1999), «Zamora. Estudios: Estudio filológico», Monumenta Palaeographica Medii Aevi, Series Hispanica. Corpus Inscriptionumn Mediaevalium, León, BrepolsUniv. León, vol. I/2, pp. 155-210.

- (2004), «Del corpus documental asturleonés al diccionario de latín medieval del reino de León (s. IX-1230)», Orígenes de las lenguas romances en el reino de Léon. Siglos IX-XII, León, Caja España y A.H.D. de León, vol. II, pp. 315-347.

PÉrez Rodríguez, Estrella (2003), «Primiclerus: estudio de un neologismo hispánico», Voces, 14, pp. 77-101.

Quadrado, José Ma -Parcerisa, Francisco J. (1989), Recuerdos y bellezas de España. Palencia, Palencia, E. Ámbito y Diputación Provincial de Palencia, facsimil de la ed. de 1861, 168 páginas.

- (1993), Recuerdos y bellezas de España. Segovia, Segovia, E. Ámbito y Diputación Provincial de Segovia, facsimil de la ed. de 1865, 238 páginas. 